\title{
The NF1 Locus Encodes a Protein Functionally Related to Mammalian GAP and Yeast IRA Proteins
}

\author{
Roymarie Ballester,; Douglas Marchuk, ${ }^{\dagger}$ \\ Mark Boguski, $\neq$ Ann Saulino, $t$ \\ Roxanne Letcher, $†$ Michael Wigler,* \\ and Francis Collins ${ }^{\dagger}$ \\ * Cold Spring Harbor Laboratory \\ Cold Spring Harbor, New York 11724 \\ t Howard Hughes Medical Institute \\ and the Departments of Internal Medicine \\ and Human Genetics \\ University of Michigan \\ Ann Arbor, Michigan 48109 \\ ¥National Center for Biotechnology Information \\ National Library of Medicine \\ National Institutes of Health \\ Bethesda, Maryland 20894
}

\section{Summary}

The von Recklinghausen neurofibromatosis locus, NF1, encodes a protein with homology restricted to the catalytic region of the RAS GTPase-activating protein, GAP, and with extensive homology to the IRA1 and IRA2 gene products of the yeast S. cerevisiae. A segment of the NF1 cDNA gene, expressed in yeast, can complement loss of IRA function and can inhibit both wild-type and mutant activated human H-ras genes that are coexpressed in yeast. Yeast expressing the NF1 segment have increased H-ras GTPase-stimulating activity. These studies indicate that the NF1 gene product can interact with RAS proteins and demonstrate structural and functional similarities and differ. ences among the GAP, IRA1, IRA2, and NF1 proteins.

\section{Introduction}

von Recklinghausen neurofibromatosis (NF1) is one of the most common autosomal dominant disorders, with an incidence of about 1 in 3000 individuals in all ethnic groups (Crowe et al., 1956; Riccardi and Eichner, 1986). The disorder has a high spontaneous mutation rate, with an estimated $40 \%-50 \%$ of NF1 cases being new mutations. The clinical features of NF1 are quite variable, but most arise in tissues derived from the neural crest. Among these are the characteristic cafe-au-lait spots, which may be due to abnormal differentiation of melanocytes, and the benign neurofibromas, which give the disorder its name. These latter are composed of a mixture of cell types including Schwann cells, fibroblasts, mast cells, and vascular elements. More serious complications of NF1 can include seizures, learning disabilities, major orthopedic abnormalities, and the development of malignancy, especially neurofibrosarcoma and optic glioma.

No consistent biochemical abnormality has been found in tissues affected by NF1, and this has slowed progress in understanding its biology. Linkage analysis has been used to map the locus to the proximal long arm of chromo- some 17 (Barker et al., 1987; Seizinger et al., 1987; Goldgar et al., 1989). Subsequent physical mapping efforts (Fountain et al., 1989; O'Connell et al., 1989) narrowed the region where the gene was located to within a few hundred kilobases. These studies culminated in the cloning and identification of the NF1 gene (Wallace et al., 1990; Viskochil et al., 1990; Cawthon et al., 1990). The initial reports delimited a large locus with a ubiquitously expressed transcript of about $13 \mathrm{~kb}$. Deletions (Viskochil et al., 1990), point mutations (Cawthon et al., 1990), and an insertion (Wallace et al., 1990) were described in NF1 patients that would imply a loss of function of this gene product as the causative mutation. Further evidence for the inactivation hypothesis comes from expression studies-of the NF1 transcript in somatic cell hybrids. The gene was shown to be transcribed from a normal human chromosome 17 in a rodent-human hybrid cell line, but not in somatic cell hybrids derived from two rare NF1 patients containing balanced chromosomal translocations involving 17q11.2 (Wallace et al., 1990). These observations are consistent with the proposal that the NF1 gene acts as a tumor suppressor (Knudson et al., 1975) and that the mechanism of action is actually recessive at the cellular level.

Further cloning and sequence analysis of the NF1 transcript (Xu et al., 1990; Buchberg et al., 1990; D. Marchuk et al., unpublished data) demonstrates that the NF1 gene product has homology with the mammalian RAS GTPaseactivating protein, GAP (Trahey and McCormick, 1987; Vogel et al., 1988; Trahey et al., 1988), as well as the products of IRA1 and IRA2, two Saccharomyces cerevisiae genes that encode functional equivalents of GAP in yeast and regulate RAS signal transduction pathways controlling cell growth (Tanaka et al., 1989, 1990a, 1990b). Expression of mammalian GAP can suppress the characteristic heat shock sensitivity phenotype of $i \mathrm{ra}^{-}$and $i \mathrm{ra2}^{-}$ mutants (Ballester et al., 1989; Tanaka et al., 1990a, 1990b), suggesting that the GAP and IRA proteins are functionally analogous in their ability to stimulate the GTPase activity of RAS. In the work reported here we have made an extensive sequence comparison of the NF1, GAP, and IRA proteins and analyzed the function of a fragment of the NF1 protein expressed in yeast.

Results

\section{Comparative Sequence Analyses}

The results of a multiple alignment analysis of the NF1, IRA1, IRA2, and GAP proteins using the MACAW program (Schuler et al., 1990) are shown in Figure 1. Interestingly, neither the amino-terminal half of GAP nor the first 400 residues of the partial NF1 sequence have anything in common with the large amino-terminal domains of IRA1 and IRA2. In the remainder of the proteins, 16 to 17 highly conserved sequence motits or homology blocks common to NF1, IRA1, and IRA2 were identified. These motifs cluster into two domains that constitute the central and carboxyterminal regions of these proteins and are composed of 


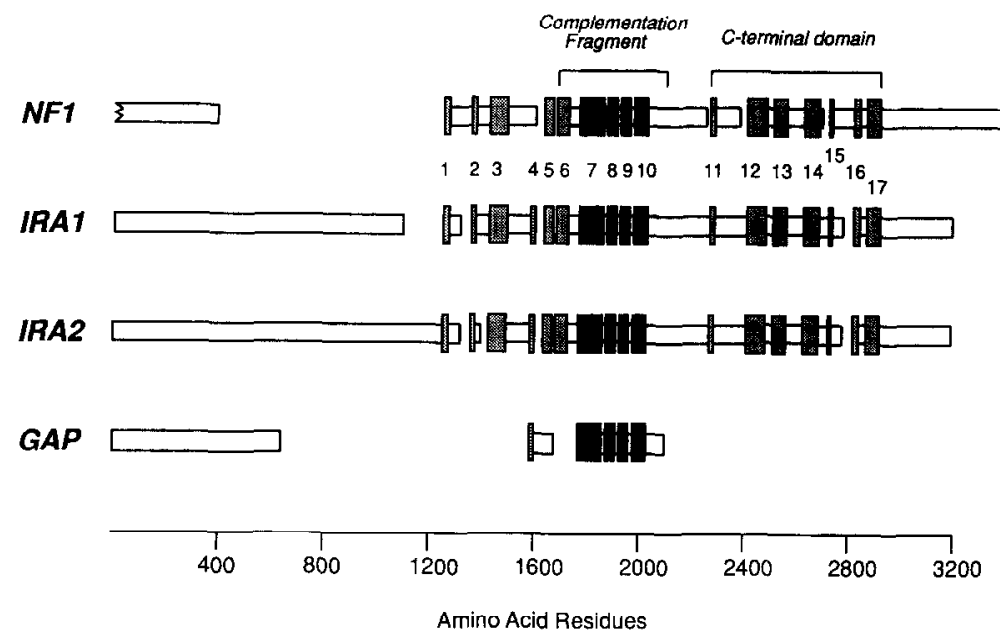

Figure 1. Sequence Domains and Motifs among NF1-Related Proteins

The MACAW program (Schuler et al., 1990) was used to locate, analyze, and assess the statistical significance of ungapped regions of local similarity (also referred to as "blocks") among the NF1, IRA1, IRA2, and GAP protein sequences. All blocks common to at least three of the four sequences, and having chance probabilities $<\sim 10^{-3}$, are shown. Unfilled rectangles indicate regions with little or no sequence conservation. Blank spaces between rectangles signify gaps in the multiple alignment. The filled rectangles labeled 1 through 17 denote conserved sequence motifs. The fragment indicated by the bracket, which includes blocks 6 through 10 and corresponds to residues 791-1203 of NF1, was the region used for the complementation experiments as described in the text. Blocks 7 through 10 indicate regions common to all four sequences and are colored black to indicate this fact. Sources of the sequence data for the four proteins shown are described in Experimental Procedures. The Karlin $\mathrm{p}$ values (Karlin and Altschul, 1990) associated with each block are as follows: block $1\left(4.39 \times 10^{-6}\right)$, block $2\left(2.57 \times 10^{-3}\right)$, block $3(0)$, block 4 $\left(1.23 \times 10^{-6}\right)$, block $5\left(9.5 \times 10^{-7}\right)$, block $6(0)$, block $7(0)$, block $8\left(2.22 \times 10^{-11}\right)$, block $9(0)$, block $10\left(3.61 \times 10^{-7}\right)$, block $11\left(9.17 \times 10^{-3}\right)$, block $12(0)$, block $13(0)$, block $14(0)$, block $15\left(5.67 \times 10^{-5}\right)$, block $16\left(1.21 \times 10^{-4}\right)$, block $17\left(1.11 \times 10^{-16}\right)$. A p value of zero indicates $p<10^{-100}$. For block 4 , the statistical significance increases when the GAP segment is removed from the alignment, signifying that the apparent relationship of the GAP segment may be due to chance (MACAW User's Manual, pp. 5-10). For all of the other blocks, the statistical significance decreases if any one sequence is removed from the alignment

Block 6 p O

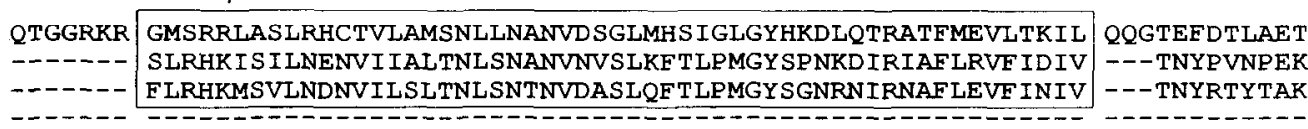

NF1

IRA1

Block 7 p 0
B

LADRFERLVELVTMMGDQGELP IAMALANVVPCS QWDELARVLVTLFDSRFLLYQLLWNMF SKEVELADSMQTI EMDKMLA IDDFLKY I I KNP ILAFFGSL- -ACSPA DVDLYAGGF LNAFDTRNASH I LVTELLKOE I KRAARSDD I DLGKLEAADKF LRYT IEHPQLSSF GAA- -VCPAS DIDAYAAGL INAFETRNATH IVVAQL IKNE IEKSSRPTDI DRTLIAS ILLRIFLHEKLESLLLCTLNDRE I SMEDEATTI

NF1

IRA1

IRA2

GAP

NF1

IRA1

IRA2

GAP

LRRNSCATRALSL YTRSRGNKYLIKTLRPVLQG IVDNKE

FRATTLASTLMEQYMKATATQFVHHALKDS ILK IMESKQ

----SFEID--KMKPGSENSEKMLDLFEKYMT

- - - FFEIE--KLKPEDSDAEROIEIFVKYMI

---SCELSPSKLEKNEDVNTNLTHLL-NILS

Block $9 \quad p \sim 0$

KFFHAIISSSSEFPPOLRSVCHCLYOUVSORFPONSIG RIIDAITSSIDDEP IELVDICKTIYNAASVNEPEYAYI --

\begin{tabular}{l|l} 
ELLES I SNSVSYFPPPLFY ICQNI YKVACEKFPDHAI I & -- \\
ELVEKIFMASE ILPP TLRY I YGCLQKSVQHKWP TNTTM & RTR
\end{tabular}

Block $10 \quad$ p<3.6e-7

KL MSKILQS IANHV-LFTKEEHMRPENDFVKSNFDAARRFFLDIA SDC--PTSDAVNHSLSF I SDGNVLALHRLLWN

IT LAKVIOSIANGRENIFKKDILVSKEEFLKTCSDKIFNE LSELC KIPTNNFTVNVREDPTP I SE-DYSFLHKFFYL

IS IAKVIONTANGSENF SRWPAICSOKDFIKECSDRIFREIAEIC RTD-RTIDIOVRTDPTPIAF-DYOFLHSFVYI

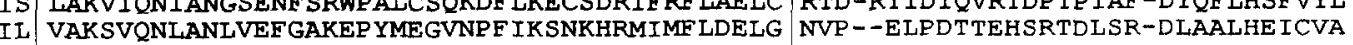

AVGSAMFLRF INPAIVSPYEAGILDKK PPPRIERG AVGSFVE LRF I GPALVSPDSENIIIVT HAF-DRKP AAGSFVELRFFCPALVSPDSENIIDIS HLS-EKRT \begin{tabular}{ll|l} 
AAGSFVELRF FCPALVSPDSEN I ID IS & HLS-EKRT \\
VVSGFVELRI ICPAILNPRMEN I I SDS & PSP IAART
\end{tabular}

NF1

IRA1

IRA2

NF1

IRA1

IRA2

GAP

NF1

IRA1

$\operatorname{IRA1}_{\text {IRA2 }}$

GAP EFT IRKE I INESK-LPGEF---SFLKNTVMLNDK I LGVLGQP SMEIK GLEVRRNVLNEAKHDDGD IDGDDF YKTTFLLIDDVLGQLGQRKMEF S SDELRT - -LSNER-GAQQHVLKKLLAITELL-QQKQNQYTKTN-DVR

Figure 2. Comparative Sequence Analysis of the NF1 Complementation Fragment

Based on the analysis in Figure 1, subsequences of NF1, IRA1, IRA2, and GAP were selected for a full dynamic programming alignment, with gaps, using the program MSA (Lipman et al., 1989). The optimal multiple alignment is shown. With respect to the highly conserved sequence blocks identified by MACAW (Figure 1), the alignments are identical except for block 5 in which MSA introduced a single-residue deletion in NF1. The probabilities of chance occurrence associated with each block were derived from the MACAW analysis (Figure 1). The subsequences used as input for program MSA correspond to residues 791-1203 for NF1 (following the numbering system of Xu et al., 1990), 1458-1852 for IRA1, 1604-2001 for IRA2, and 745-1044 for human GAP. 
blocks 1 through 10 and 11 through 17, respectively. When the GAP sequence is included in the analysis, only four blocks (7-10) remain common to all four sequences. An additional small region (block 4, 24 residues) of questionable significance may be present in the IRA sequences and GAP but not NF1 (Figure 1). Thus only a very limited region of 223-232 residues (blocks 7 through 10 in Figure 2) appears to be conserved among all four sequences. This is considerably smaller than previous estimates of the GAP catalytic domain (Tanaka et al., 1989, 1990a, 1990b; Xu et al., 1990).

Once the most highly conserved blocks corresponding to the GAP catalytic domain were mapped using MACAW, these short, approximately equal subsequences were extracted for an optimal global alignment using the MSA program (Lipman et al., 1989). The results are shown in Figure 2. The probability that blocks 6 through 10 are related by chance is vanishingly small despite the fact that only $5 \%-23 \%$ of identical residues are present among all four sequences in these regions. In particular, block 7 contains only four 4-way identities across a 78 residue span, yet the probability that this pattern is ascribable to chance is essentially zero. Using older analytic methods, it would be difficult to attach this degree of significance to similarity so diffuse. In the interblock regions, the sizes and locations of gaps are consistent among the sequences. In contrast, the regions distal to block 10 display much more variability in the sizes and locations of gaps.

\section{Design of the NF1 Expression Vector}

A region (amino acids 791-1203) spanning the proposed catalytic domain of NF1 (see Figure 1) was amplified by polymerase chain reaction (PCR) from a fetal brain cDNA library (see Experimental Procedures) and cloned into the yeast expression vector pADANS (see Figure 3), creating pADANS-NF1. A single nucleotide difference was observed, at nucleotide position 3407 of the published sequence (Xu et al., 1990). This $T$ to $C$ transition would result in an isoleucine to threonine substitution. This difference was subsequently observed in two out of four independent PCR clones and therefore may reflect a true genetic polymorphism.

The PADANS vector derives from the pADNS plasmid (Colicelli et al., 1989), which is an expression vector designed to express cDNA genes from the alcohol dehydrogenase $(A D H 1)$ promoter. pADANS also contains the LEU2 marker and replicates to high copy in yeast extrachromosomally because it contains the $2 \mu$ circle origin of replication. pADNS is used as a control plasmid in the expression studies described below. pADANS differs from pADNS only in that the $A D H 1$-driven transcript includes the first 14 codons of the ADH1 gene. In pADANS-NF1, these codons are in frame with the NF1 coding sequences. In addition to pADNS and pADANS-NF1, we have also used the plasmid pADGAP, which expresses a full-length human GAP cDNA clone driven by the $A D H 1$ promoter (Ballester et al., 1989). pADGAP likewise contains the LEU2 marker and the $2 \mu$ circle origin of replication.

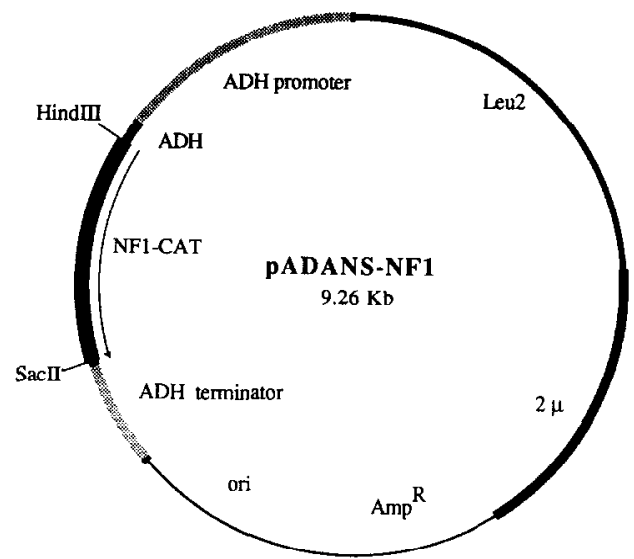

Figure 3. Diagram of the NF1 Expression Vector

The pADANS vector will be described in detail in Colicelli et al. (1991) In addition to bacterial plasmid sequences, pADANS-NF1 contains a selectable marker ( $L E U 2$ ) and origin of replication $(2 \mu)$ for use in yeast. The vector also contains the yeast $A D H 1$ promoter and first 14 codons of the gene, as well as the $A D H 1$ terminator. The NF1 catalytic domain (see Figure 2) has been inserted in frame as a fusion peptide with $A D H 1$. Further details of the construction of the clone are described in Experimental Procedures.

\section{Complementation of ira- Strains by NF1}

Disruption of either IRA gene leads to a phenotype that resembles that seen in cells containing the mutationally activated RAS2 ${ }^{\text {Val-19 }}$ (Toda et al., 1985; Sass et al., 1986; Matsumoto et al., 1985; Tanaka et al., 1989, 1990a, 1990b). In particular, ira1- or ira2- strains are exquisitely sensitive to heat shock. This phenotype is suppressed by the overexpression of the yeast phosphodiesterase gene, PDE2, which also suppresses the phenotype resulting from the activated yeast $R A S 2^{\text {Val-19 }}$ (Tanaka et al., 1989; Sass et al., 1986). PDE2 expression undoubtedly counteracts the effects of activated RAS protein upon adenylyl cyclase, the main target of RAS action in S. cerevisiae (Toda et al., 1985; Sass et al., 1986), by lowering cAMP levels. We and others have previously shown that expression of the human GAP gene in ira1- yeast strains suppresses heat shock sensitivity (Ballester et al., 1989; Tanaka et al., 1990a). Expression of the GAP gene does not suppress the heat shock sensitivity resulting from the mutant acti-

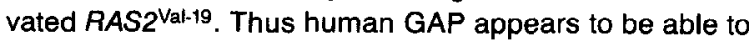
inhibit the function of wild-type yeast $R A S$ protein, but not that of mutationally activated RAS protein.

We have tested the effect of expressing the human NFy gene upon the phenotype of ira $^{-}$and $R A S 2^{\text {Val-19 }}$ strains. In the first of a series of experiments (Figure 4A), the ira ${ }^{-}$ strain IR-1 (see Table 1 for strain description) was transformed with either of four plasmids: pADNS, PADGAP, pADANS-NF1, or pPDE2. The plasmid pPDE2 contains the yeast $P D E 2$ gene, together with the LEU2 marker and the $2 \mu$ circle origin of replication (Sass et al., 1986). Three independent transformants were picked from each transformation, and patches were tested for heat shock sensitivity by a replica plate method (see Experimental Proce- 


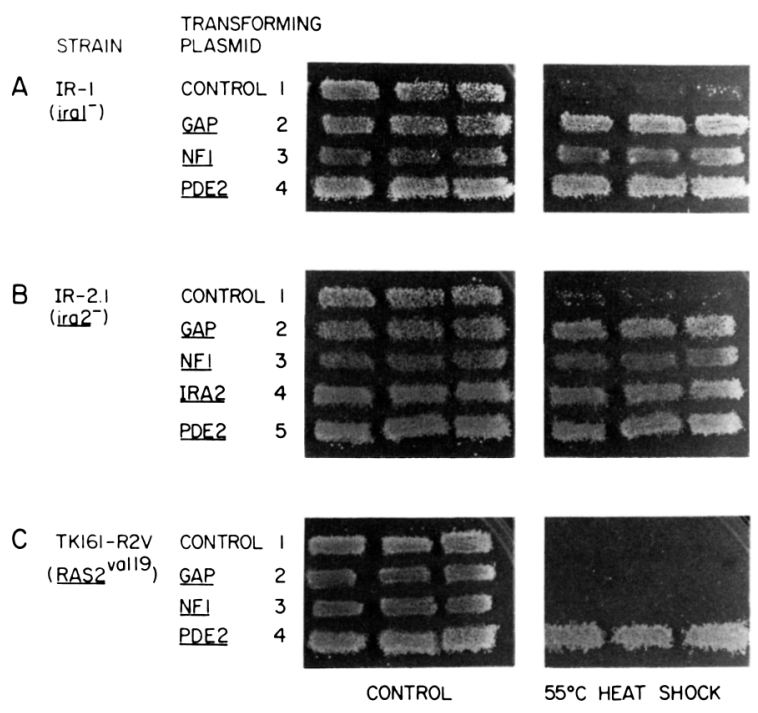

Figure 4. Effect of Expressing NF1 on the Heat Shock Sensitivity of Strains Lacking IRA1 or IRA2 and Strains Containing RAS2val-19 Yeast strains were transformed with various plasmids containing the LEU2 gene and plated onto SC-Leu plates. Independent transformants were patched onto SC-Leu plates, incubated at $30^{\circ} \mathrm{C}$ for 2 days, replica plated onto SC-Leu plates, and heat shocked $\left(\right.$ at $55^{\circ} \mathrm{C}$ ) for $10 \mathrm{~min}(\mathrm{~A})$, $5 \mathrm{~min}(\mathrm{~B}$ and $\mathrm{C}$ ), or $0 \mathrm{~min}$ (A, B. and $\mathrm{C}$ ) (CONTROL). After heat shock treatment the plates were incubated at $30^{\circ} \mathrm{C}$ for 2 days. The strains used are IR-1, a strain that contains a disrupted chromosomal IRA1 gene (A); IR-2.1, a strain that contains a disrupted chromosomal IRA2 gene (B); and TK161-R2V, a strain that contains the RAS2 $2^{\mathrm{Val}-19}$ allele (C) (see Table 1 for description of the strains). The different strains were transformed with pADNS, a control plasmid (rows 1); PADGAP, a plasmid containing the human GAP gene (rows 2); PADANS-NF1, a plasmid expressing the catalytic domain of the NF1 gene (rows 3); YepPDE2, a plasmid containing a yeast cAMP phosphodiesterase gene ( $A$, row 4), (B, row 5), (C, row 4); and pYep/RA2, a plasmid containing the IRA2 gene $\{\mathrm{B}$, row 4).

dures). As has been shown previously, expression of human GAP or PDE2 suppresses the phenotype of an irat- strain. In addition, expression of the catalytic domain of the NF1 gene also suppresses the heat shocksensitive phenotype of IR-1.

This experimental format was repeated with an ira2strain, IR-2.1. As before, expression of GAP, NF1, or PDE2 suppresses the heat shock-sensitive phenotype (Figure 4B). Suppression of heat shock sensitivity was also demonstrated in ra $^{-}$and ira2 ${ }^{-}$strains expressing NF1 in the vector pADNS, which contained the $T$ (isoleucine) polymorphism at position 2047 (data not shown). Finally, the format was repeated in a RAS2Val-19 strain, TK161-R2V. In this strain only expression of the PDE2 gene suppresses the heat shock-sensitive phenotype (Figure 4C). These results indicate that both GAP and NF1 proteins are capable of inhiblting wild-type yeast RAS proteins, but nelther can inhibit the mutationally activated RAS2 $2^{\text {val-19 }}$ protein.

\section{Inhibition of Wild-Type and Mutant Mammalian} H-ras Protein by NF1

We have previously demonstrated that human GAP can inhibit the wild-type human $\mathrm{H}$-ras protein when both are expressed in yeast (Ballester et al., 1989). This is demon-

\begin{tabular}{|c|c|}
\hline Strain & Genotype \\
\hline SP1a & MATa his3 leu2 ura 3 trp1 ade 8 can1 \\
\hline IR-1 ${ }^{b}$ & MATa his3 leu2 ura3 trp1 ade8 can1 ira $1:$ HIS3 \\
\hline IR-2.1 ${ }^{c}$ & MATa his3 leu2 ure3 trp1 ade8 can1 ira2::URA3 \\
\hline TK161-R2V & MATe his3 leu2 ura3 trp1 ade8 can1 RAS2 Val-19 \\
\hline TTRB-G1 & $\begin{array}{l}\text { MAT } \alpha \text { his3 leu2 ura3 trp1 ade8 can1 cdc25::URA3 } \\
\text { pAHRG-H1d }\end{array}$ \\
\hline TTRB-V $2^{b}$ & $\begin{array}{l}\text { MATa his3 leu2 ura3 trp1 ade8 can1 cdc25::URA3 } \\
\text { PAHRV-H2 }\end{array}$ \\
\hline \multicolumn{2}{|c|}{$\begin{array}{l}\text { a Toda et al. (1985). } \\
\text { ' Ballester et al. (1989). } \\
\text { c See Experimental Procedures, Construction of Yeast Strains. } \\
\text { d See Experimental Procedures, Plasmids. }\end{array}$} \\
\hline
\end{tabular}

strated most readily in strains with a cdc25- background. The product of the $C D C 25$ gene appears required for the catalytic activation of wild-type yeast RAS proteins (Broek et al., 1987; Robinson et al., 1987; Camonis et al., 1986; Powers et al., 1989). cdc25- cells are not viable, but cdc25- strains that express the human $\mathrm{H}$-ras gene are (Marshall et al., 1987). We believe that the human H-ras protein does not require catalytic activation by the $\mathrm{CDC} 25$ gene product in yeast because it is relatively insensitive to the action of the IRA1 and IRA2 gene products (Tanaka et al., 1990a). We previously showed that $c d c 25^{-}$strains that express both the human H-ras and GAP genes are temperature sensitive. By contrast, $c d c 25^{-}$strains that express the human GAP and the mutationally activated $\mathrm{H}$-ras ${ }^{\mathrm{Val}}{ }^{12}$ "gene are not temperature sensitive. We interpreted these results to mean that human GAP can downregulate wild-type $\mathrm{H}$-ras protein but can neither downregulate nor interfere with the activated $\mathrm{H}$-ras ${ }^{\mathrm{Val}-12}$ protein (Ballester et al., 1989).

We have repeated these experiments using yeast strains that contain the NF1 expression vector, pADANS-NF1. The cdc25- strain expressing human wild-type H-ras, TTRBG1 (Figure 5B), or the cdc25- strain expressing the activated $\mathrm{H}$-ras ${ }^{\text {Val-12, }}$, TTRB-V2 (Figure 5A), was transformed with pADNS, PADGAP, or PADANS-NF1, and eight independent transformants of each were tested in patches for temperature sensitivity by a replica plate method. The results obtained with transformants expressing GAP were the same as seen previously. In particular, cdc25- H-ras strains expressing GAP were temperature sensitive, while cdc25- H-ras ${ }^{\mathrm{Val}-12}$ strains expressing GAP were not. We found that $c d c 25^{-} \mathrm{H}$-ras strains expressing the catalytic domain of NF1 were also inhibited for growth at elevated temperatures. Unlike colc25- $\mathrm{H}$-ras $\mathrm{Val}-12$ strains expressing GAP, however, cdc25 $\mathrm{H}$-rasval-12 strains expressing NF1 were temperature sensitive. Thus not only does NF1 inhibit wild-type $\mathrm{H}$-ras protein, but it also appears to be capable of inhibiting the function of the mutant H-ras Val-12 protein. In this respect, the NF1 expression vector differs from the GAP expression vector.

\section{Biochemical Assays of Yeast Expressing NF1}

While our genetic experiments clearly indicate that the human NF1 protein, like GAP, interacts with both yeast and mammalian RAS proteins, they do not indicate if the NF1 


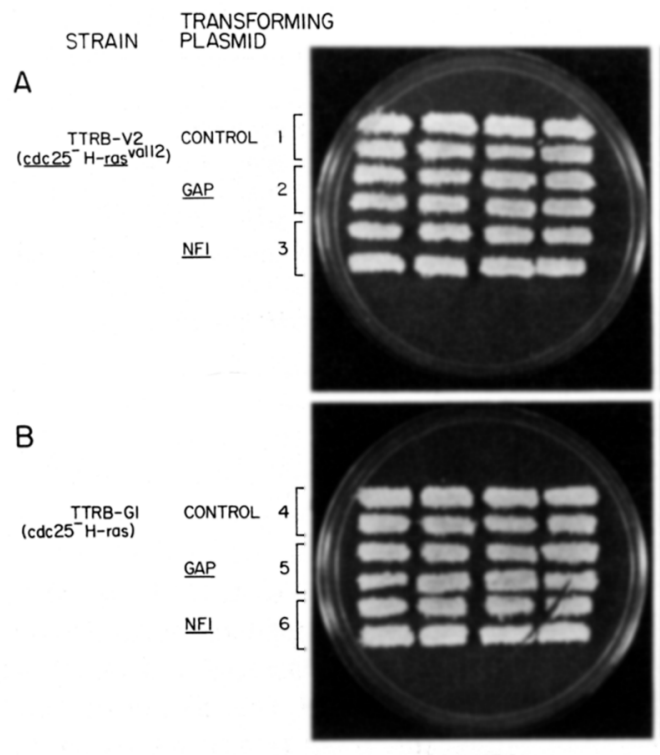

CONTROL

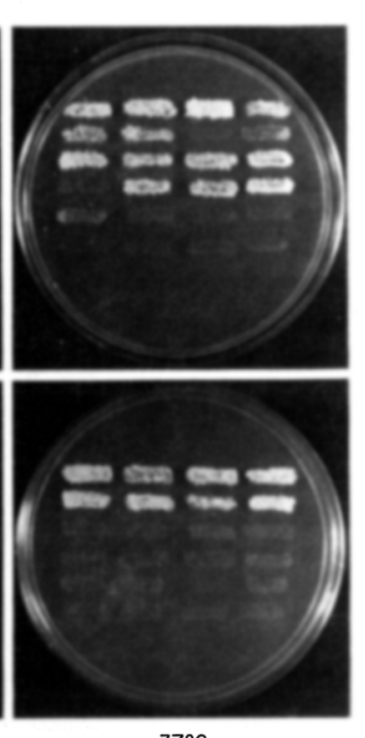

$37^{\circ} \mathrm{C}$

Figure 5. Effect of Expressing NF1 on the Temperature Sensitivity of Strains Lacking CDC25 and Expressing the Mutant H-ras ${ }^{\text {Val-12 }}$ or the Wild-Type Human H-ras Proteins

Cells lacking the CDC25 gene, and expressing (A) the mutant $\mathrm{H}$-rasval-12 gene (plasmid PAHRV-H2, strain TTRB-V2), or (B) the wildtype $\mathrm{H}$-ras gene (plasmid pAHRG-H1, strain TTRB-G1), were transformed with a control plasmid, pADNS (rows 1 and 4), a plasmid expressing GAP, pADGAP (rows 2 and 5), or a plasmid expressing the catalytic domain of the NF1 gene, pADANS-NF1 (rows 3 and 6). Independent $\mathrm{LeU}^{+}$transformants were patched onto selective plates and incubated at room temperature for 3 days and then replica plated onto YPD plates. Replicas were incubated at room temperature (CONTROL) or at $37^{\circ} \mathrm{C}$ for 3 days. Each set shows eight independent transformants.

protein, like GAP, has GTPase-stimulating activity. To answer this question, we performed H-ras GTPase assays using crude lysates of cells that express human GAP or human $\mathrm{NF1}$, adding wild-type or mutant $\mathrm{H}$-ras proteins purified from Escherichia coli expression systems (Gross et al., 1985). This approach is feasible since we have previously observed no H-ras GTPase-stimulating activity in lysates from S. cerevisiae strains (R. B., unpublished data; Adari et al., 1988). Lysates were prepared from the ira2yeast strain (IR-2.1) that had been transformed either with a control vector ( $P A D N S)$ or vectors expressing human GAP (pADGAP), NF1 protein (pADANS-NF1), or yeast IRA2 protein (pYep-IRA2). H-ras protein, which was bound with radiolabeled GTP, hydrolyzed GTP to about the same

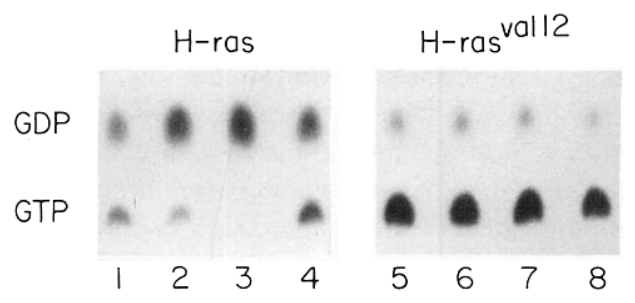

Figure 6. Stimulation of the Human H-ras GTPase Activity by Lysates from Yeast Strains Expressing the NF1 Protein or Human GAP Wild-type human H-ras (lanes 1-4) or mutant $\mathrm{H}$-ras Val-12 (lanes 5-8) proteins prelabeled with [ $a-32$ ] $]$ GTP were incubated for $30 \mathrm{~min}$ at room temperature with extracts of the ira2- yeast strain IR-2.1 transformed with the control plasmid, pADNS (lanes 1 and 5); the plasmid expressing the catalytic domain of the NFI gene, PADANS-NF1 (lanes 2 and 6); the plasmid expressing the human GAP gene, pADGAP (lanes 3 and 7); and the plasmid expressing the IRA2 gene, pYep/RA2 (lanes 4 and 8 ). The H-ras protein was then immunoprecipitated with the monocional antibody $Y 13-259$ and incubated with rabbit anti-rat immunoglobulin and protein A-Sepharose. The labeled nucleotides were eluted and resolved by thin-layer chromatography (see Experimental Procedures for a detailed description). The figure shows the autoradiograph of plates exposed on X-ray film. Results of the quantitation of the plate are shown in Table 2. extent whether incubated with assay buffer or with lysates from yeast transformed with either vector controls or pYepIRA2 (data not shown).

Compared to control lysates, GTP hydrolysis by H-ras was greatly accelerated by incubation with lysates from yeast expressing GAP (see Figure 6 and Table 2), and hydrolysis was moderately but definitely accelerated when $\mathrm{H}$-ras was incubated with lysates from yeast expressing NF1. From the stoichiometry of the GTPase-stimulating assays (see Experimental Procedures), we cannot infer that NF1 acts catalytically on H-ras. Neither lysate was capable of accelerating the GTP hydrolysis by the mutant activated $\mathrm{H}$-ras ${ }^{\mathrm{Val}-12}$ protein. The results of three separate experiments with independently prepared lysates are

\begin{tabular}{|c|c|c|c|c|c|c|c|c|}
\hline \multirow[b]{3}{*}{ Experiment $^{\mathrm{a}}$} & \multicolumn{8}{|c|}{ Proportion of Protein Bound with GDP } \\
\hline & \multicolumn{4}{|l|}{ H-ras } & \multicolumn{4}{|c|}{ H-ras Val-12 } \\
\hline & Control & GAP & NF1 & IRA2 & Control & GAP & NF1 & IRA2 \\
\hline 1 & 0.47 & 0.81 & 0.62 & 0.50 & 0.05 & 0.11 & 0.10 & 0.11 \\
\hline $2^{b}$ & 0.61 & 0.96 & 0.82 & 0.57 & 0.11 & 0.14 & 0.12 & 0.13 \\
\hline 3 & 0.70 & 0.97 & 0.91 & 0.65 & 0.20 & 0.13 & 0.15 & 0.13 \\
\hline
\end{tabular}

Human $\mathrm{H}$-ras or $\mathrm{H}$-ras ${ }^{\mathrm{Va}-12}$ proteins prebound to $a^{32}$ PIGTP were incubated with yeast extracts as described in Figure 6 and Experimental Procedures. The bound nucleotides were eluted and resolved by thin-layer chromatography. The chromatography plates were scanned and analyzed using the Phosphorlmager from Molecular Dynamics as described in Experimental Procedures. The results are presented as the proportion of the total counts recovered as GDP from the H-res proteins, after subtracting background. Lysates were prepared from the yeast strain IR-2.1 (ira2) transformed with either control plasmids pADNS, or plasmids expressing the indicated proteins. See text for more detail.

a Three separate experiments were performed using independently prepared lysates.

${ }^{b}$ The autoradiograph shown in Figure 6 is the result of this experiment. 
shown in Table 2. We conclude that, relative to control lysates, lysates from cells containing the NF1 expression vector have increased $\mathrm{H}$-ras GTPase-stimulating activity. Under our assay conditions, NF1 lysates have less activity than lysates from celis expressing GAP.

\section{Discussion}

The NF1 locus encodes a protein that is structurally related to the IRA proteins of yeast and to the GAP protein of mammalian cells (Xu et al., 1990; Buchberg et al., 1990). New software tools (Altschul et al., 1990; Schuler et al., 1990) and statistical methods (Karlin and Altschul, 1990) enabled us to analyze in detail the conserved sequence regions of these proteins and make an assessment of their statistical significance. By these quantitative criteria, the homologies among NF1, IRA1, IRA2, and GAP proteins are unquestionably of a very high level of significance (Figures 1 and 2). While the similarity of NF1 to GAP is limited to blocks 7-10 in the catalytic domain, the similarity of NF1 to IRA1 and IRA2 extends well outside this, in both directions, especially in the C-terminal domain, where blocks 12 through 16 are as highly conserved and significant as those in the catalytic domain. Extensive local and global pairwise comparisons indicate that NF1 is much more similar to the yeast sequences than to GAP, and is closest to IRA2, particularly in the C-terminal domain (M. Boguski, unpublished data).

GAP and IRA proteins are known to interact with RAS proteins. The presumption that the NF1 protein also can interact with RAS proteins is confirmed by our studies. We have expressed in yeast the domain of the NF1 protein that corresponds to the common catalytic region of GAP and the IRA proteins. Expression of the NF1 catalytic domain, like the expression of GAP, complements IRAdeficient yeast and also inhibits the wild-type human $H$-ras protein expressed in yeast. Unlike GAP, expression of NF1 inhibits even the activated $\mathrm{H}$-ras ${ }^{\mathrm{Val}-12}$ protein. We have found increases in H-ras GTPase-stimulating activity in lysates of yeast expressing the NF1 catalytic region, although not as much as found in lysates of yeast expressing GAP. These last two observations suggest to us that the expressed NF1 protein fragment might bind more tightly to H-ras proteins than does GAP. Hence, this NF1 protein would display less GAP-like catalytic activity yet would be capable of inhibiting the activated form of $\mathrm{H}$-ras. Further biochemical studies are needed to confirm this idea with the full-length NF1 protein.

We have explored the function of only the common catalytic region of NF1. As the sequence analysis we and others have presented shows (Xu et al., 1990; Buchberg et al., 1990), NF1 is highly related to the yeast IRA proeins in carboxy-terminal regions-regions that show no homology with GAP. It seems highly probable to us that these structurally conserved regions have conserved biochemical functions as well. These regions of homology should be subjected to future genetic and biochemical experimentation.

von Recklinghausen neurofibromatosis can be viewed as an autosomal disorder affecting both the cellular proliferation and differentiation of cells of neuroectodermal origin. Prior to the recent identification of the NF1 gene by positional cloning methods, efforts to identify a biochemical marker of the disease had failed. While only a few mutations of the NF1 gene have been identified thus far in patients with the disease, it appears that inactivation of the gene, rather than activation, leads to the appearance of the disorder. This observation would be consistent with a tumor suppressor mechanism, although direct evidence for somatic inactivation of the remaining normal NF1 allele in tumors has not yet been reported.

The functional linkage between NF1 and RAS is highly gratifying since oncoproteins in general, and RAS proteins in particular, are known to profoundly affect cellular proliferation and differentiation. Mutant, activated RAS genes have been found in neuroblastomas (Shimizu et al., 1983), where, presumably, RAS proteins stimulate cellular proliferation. On the other hand, in some cells, such as rat $\mathrm{PC} 12$ cells, which are also derived from tumors of neuroectodermal origin, activated RAS induces differentiation and causes the cessation of growth (Bar-Sagi and Feramisco, 1985; Noda et al., 1985). In such cells, microinjection of blocking antibodies or transfection with interfering RAS genes does not inhibit growth, but rather blocks the differentiation induced by nerve growth factor (Hagag et al., 1986; Szeberenyi et al., 1990). In the absence of information about the role of RAS in the neuroectoderm in vivo, and in the absence of knowledge about whether NF1 regulates or mediates RAS function, several mechanisms might explain the disorders of proliferation and differentiation found in NF1 patients. In view of the ubiquitous expression of NF1 (Wallace et al., 1990), it is not currently apparent why the disease appears so prominently in neural crest derivatives.

RAS proteins, which are found ubiquitously in eukaryotes, bind and hydrolyze GTP, and are in their active configuration when GTP bound (for review see Barbacid, 1987). GAP was discovered as the major factor in cellular lysates that stimulates GTP hydrolysis by RAS. GTP hydrolysis by oncogenic forms of RAS proteins is generally resistant to stimulation by GAP (Trahey and McCormick, 1987; Adari et al., 1988; Cales et al., 1988), and hence many have proposed that GAP down-regulates wild-type RAS proteins. This hypothesis has been strengthened by two sets of observations. First, GAP is homologous to yeast IRA proteins (Tanaka et al., 1989, 1990a, 1990b), and GAP expression can complement IRA-deficient yeast (Ballester et al., 1989; Tanaka et al., 1990a). In yeast it is amply clear that the IRA proteins regulate RAS. Second, expression of GAP can inhibit the growth transformation of cultured cells induced by wild-type RAS (Zhang et al., 1990).

It is by no means clear that the only function of GAP and IRA proteins is to regulate RAS proteins. Both GAP and IRA proteins, and for that matter the NF1 protein, are very large molecules, but the domain required for stimulating GTP hydrolysis is much smaller (Marshall et al., 1989; Tanaka et al., 1990b). No one has yet properly addressed the issue of whether the IRA proteins have additional functions in yeast. Moreover, there is at least one in vitro sys- 
tem in which GAP and RAS proteins appear to act in concert (Yatani et al., 1990). Thus it is possible that proteins like GAP, IRA1, IRA2, and NF1 can mediate some of the effects of RAS proteins.

Our present knowledge of the IRA and GAP proteins provides only an incomplete guide for understanding the action of NF1. We cannot confidently anticipate, at present, whether NF1 proteins will act upstream or downstream of RAS, or potentially be capable of both functions. On the other hand, experimental manipulation of cells that lack NF1 protein might illuminate its functional relationship with RAS. By introducing forms of RAS protein that interfere with wild-type RAS function into such cells we may be able to discern if lack of NF1 activates the RAS pathway or blocks it.

\section{Experimental Procedures}

\section{Comparative Sequence Analyses}

Sequence motifs common among NF1-related proteins were identified and their statistical significance was estimated using the Multiple Sequence Alignment Construction and Analysis Workbench, or MACAW, program (Schuler et al., 1990). Multiple alignment is the method of choice for detecting patterns or motifs common to a set of sequences, but there are two approaches to multiple alignment that need to be considered in the context of the sequences under study. Global alignment methods are most appropriate to sequences that are small $<500$ residues), approximately equal in length, and share a global, but perhaps distant, relationship (Lipman et al., 1989). Local alignment methods, on the other hand, are preferable for longer sequences that vary greatly in length and may share only isolated regions of similarity separated by variable-length segments of little or no sequence conservation (Posfai et al., 1989; Schuler et al., 1990). The NF1-related sequences considered here come under this latter category.

Amino acid sequences used in the analysis include the 2484 residue partial sequence of human NF1 (Xu et al., 1990), the 2938 residue sequence of S. cerevisiae IRA1 (retrieval code A30135, PIR release 25.0), the 3079 residue sequence of $S$. cerevisiae IRA2 (accession number M33779, GenBank/GenPept New Sequences), and the 1044 residue sequence of the human GAP " $\mathrm{A}$ " protein (accession numbe M23379, GenBank release 63.0). The analysis was begun at a threshold of 50 and with the requirement that homology blocks be present in all four sequences. Then the scoring criteria were progressively relaxed until all statistically significant $\left(p<1.0 \times 10^{-3}\right)$ motifs common to at least three of the four sequences were identified. Because of this latter requirement, the full extent of the pairwise, global similarity between IRA1 and IRA2 is not represented in the analysis.

A major advantage of local alignment methods is that a new theory for estimating the statistical significance of sequence similarities (Karlin and Altschul, 1990; Schuler et al., 1990) can be applied to the ungapped homology blocks obtained. However, global alignment methods using dynamic programming are superior for determining the locations and extents of insertion and deletion mutations (Lipman et al., 1989). Also sequence weighting to control for redundancy in the data can be applied (Altschul et al., 1989). The two approaches were combined by computing an optimal multiple alignment of subsequences from the catalytic domain (encompassing the complementation fragment) with the MSA program (Lipman et al., 1989) using a sequence weighting procedure (Altschul et al., 1989) to control for the greater pairwise similarity of IRA1 and IRA2.

\section{Media, Genetic Manipulations, and Nomenclature}

Yeast were grown in YPD (2\% peptone, $1 \%$ yeast extract, $2 \%$ glucose) or in synthetic medium ( $0.67 \mathrm{~g} /$ liter yeast nitrogen base, $2 \%$ glucose, and appropriate auxotrophic supplements). Standard yeast genetic methods were followed as described previously (Sherman et al., 1986) The lithium acetate method was used for transformation of yeast cells (Ito et al., 1983)
Wild-type alleles and dominant mutations are denoted by capital letters, recessive mutations by lowercase italicized letters, and gene disruptions by lowercase letters, which represent the disrupted gene, followed by two colons and the auxotrophic gene marker used for the disruption. For example, ira1::HIS3 indicates the IRA1 gene was disrupted by the HIS3 marker. In the text, gene disruptions are abbreviated by lowercase italized letters representing the gene followed by a superscript minus sign, such as ira ${ }^{-}$.

DNA Manipulation

DNA manipulations were performed by standard methods (Maniatis et al., 1982). DNA restriction endonucleases, polymerases, and ligases were used under conditions recommended by suppliers (New England Biolabs, Bethesda Research Laboratories, or Perkin-Elmer Cetus). For gene disruption experiments, suitable linear DNA fragments were isolated and used for transformation of yeast cells as described (Rothstein, 1983).

\section{Plasmids}

The cloning vector pADANS (Colicelli et al., 1991) is a derivative of pADNS previously described (Colicelli et al., 1989). It contains the LEU2 gene, an Hpal-Hindlll fragment from the $2 \mu$ circle including the origin of replication, an Sspl-EcoRl fragment containing the ampicillin resistance gene from the plasmid pUC18, an EcoRI-Hindll fragment containing the promoter and the first 14 codons of the $S$. cerevisiae $A D H 1$ gene, and a Hind II-BamHI fragment containing the ADH1 terminator sequences. The promoter and terminator sequences are separated by a polylinker containing unique HindIII and Sacll sites.

The plasmid pADANS-NF1 was constructed as follows. A region spanning the proposed catalytic domain of NF1 (Figure 1) was amplified by PCR using DNA from a human fetal brain CDNA library (Stratagene, catalog number 936206) as the template. Primers were $5^{\prime}$ CATCAACCTTGTGCGCAAACAGGTGGCAGGAAAC for the amino terminus of the catalytic domain and 5'-CATGCCGCGGTCAGTGTGTAT. CTGCCACAGGTTTG for the carboxyl terminus of the domain. These primers included either a Hindill site (amino-terminal) or a Sacll site (carboxy-terminal) plus 4 bases at the $5^{\prime}$ end to facilitate digestion. The amplified PCR product was digested with HindIII and Sacll and ligated into the vector pADANS, cut with the same enzymes. The accuracy of the clone was confirmed by dideoxy sequencing (Sequenase kit, US Biochemical Corp., version 2.0) of the PCR insert encoding the catalytic domain.

The plasmid pADGAP contains the entire coding region of the human GAP gene on a high copy $L E U 2$ plasmid containing the $A D H 1$ promoter and terminator sequences, pAD4 $\triangle$ (Ballester et al., 1989). The YepPDE2 plasmid contains the yeast PDE2 gene on the high copy LEU2 plasmid, YEp13 (Sass et al., 1986). The PDE2 gene encodes a high affinity CAMP phosphodiesterase.

The plasmid pYep/RA2 contains the yeast IRA2 gene on the high copy LEU2 plasmid Yep13M4. The IRA2 gene was isolated as a high copy suppressor of the heat shock-sensitive phenotype of a strain, IR-1 (Ballester et al., 1989), with a disruption of the IRA1 gene. The gene was cloned from a library in the yeast vector Yep13M4 constructed by J. Nikawa (unpublished data). The cloned gene was identified as IRA2 by sequencing a portion of the gene that codes for amino acids 1374-1446 of the published sequence (Tanaka et al., 1990b) and by restriction endonuclease mapping. The DNA isolated is a partial clone that contains $2 \mathrm{~kb} 5^{\prime}$ of the coding sequence and extends only to the BamHI site $3^{\prime}$ of the catalytic domain (see Tanaka et al., 1990b).

The plasmid pAHRG-H1 contains the human $\mathrm{H}$-ras cDNA driven by the $A D H 1$ promoter in the vector pHV1. pHV1 is a high copy number vector that contains the polylinker from pUC18, the HIS3 gene, and an Hpal-HindIII fragment from the $2 \mu$ circle, including the origin of replication. The plasmid pAHRV-H2 is the same as PAHRG-H1 except that it contains the mutant $\mathrm{H}$-ras ${ }^{\mathrm{Val}-12}$ instead of the wild-type $\mathrm{H}$-ras. The construction of these plasmids has been described previously (Ballester et al., 1989).

\section{Construction of the ira2- Strain}

The yeast strain IR-2.1 (MATa his3 leu2 ura3 trp1 ade8 can1 ira2::URA3) containing a disruption in the IRA2 gene was constructed as follows: a BamHI DNA fragment from pYep/RA2 was inserted into pUC118 (Vieira and Messing, 1987), which had been digested with BamHI. The 
resulting plasmid was digested with Mlul and Stul, filled in with Klenow fragment, and ligated with a filled-in Hindlil fragment of the URA3 gene. This results in the deletion of the $5^{\prime}$ coding sequences of the gene including approximately 700 bases of the noncoding sequence. The resulting plasmid was used to carry out gene replacement experiments (Rothstein, 1983). A yeast haploid auxotroph, SP1, was transformed with the Sall-digested plasmid containing the deleted IRA2 gene, and transformants were selected by uridine prototrophy. Southern hybridization analysis was used to verify that the IRA2 gene was replaced by the disrupted gene.

\section{Heat Shock Sensitivity Assay}

Heat shock sensitivity was determined as described previously (Toda et al., 1985; Sass et al., 1986). Heat shock was performed by replica plating cells to a plate preheated for $1 \mathrm{hr}$ at $55^{\circ} \mathrm{C}$. This plate was then incubated for 5 or $10 \mathrm{~min}$ at $55^{\circ} \mathrm{C}$ and transferred to $30^{\circ} \mathrm{C}$ for 2 days and photographed.

\section{Preparation of Cell Lysates, GAP Assays, and Quantitation}

Yeast strains were grown to saturation in selective media and harvested by centrifugation. Cell pellets were resuspended in buffer $A$ ( 20 $\mathrm{mM}$ Tris- $\mathrm{HCl}$ [pH 7.5], $50 \mathrm{mM} \mathrm{NaCl}, 5 \mathrm{mM} \mathrm{MgCl}$ ) with $1 \% \mathrm{NP}-40,1$ $\mu \mathrm{g} / \mathrm{ml}$ each of aprotinin and pepstatin, and $1 \mathrm{mM}$ phenylmethylsulfonyl fluoride. The cells were lysed by vortexing in Eppendorf tubes containing zirconium beads (Biospec Products). The lysates were centrifuged at $4^{\circ} \mathrm{C}$ for $2 \mathrm{~min}$ in an Eppendorf centrifuge, and the supernatant was used in the GAP assays.

GAP assays were performed according to Trahey and McCormick (1987). Purified H-ras p21 (1.5 $\mu \mathrm{g}$ ) (Gross et al., 1985) was prebound to GTP by incubation for $30 \mathrm{~min}$ at $30^{\circ} \mathrm{C}$ in buffer $\mathrm{B}(20 \mathrm{mM}$ Tris- $\mathrm{HCl}$ [pH 7.5], $20 \mathrm{mM} \mathrm{NaCl}, 2.5 \mathrm{mM} \mathrm{MgCl}$ ) with $3 \mu \mathrm{M}$ GTP, $20 \mu \mathrm{Ci}$ of [ $\alpha$-32P]GTP (3000 $\mathrm{mCi} / \mathrm{mmol}$; New England Nuclear), $1 \mathrm{mM} \mathrm{ATP,} \mathrm{and}$ $1 \mathrm{mg} / \mathrm{ml}$ bovine serum albumin in a volume of $20 \mu \mathrm{l}$. The cell lysates, $0.4 \mathrm{mg}$ in $20 \mu \mathrm{l}$, were incubated with $2 \mu \mathrm{l}$ of p21 prebound to GTP for $30 \mathrm{~min}$ at room temperature. The samples were then diluted to $200 \mu \mathrm{l}$ with buffer $A$ and incubated for $30 \mathrm{~min}$ at $4^{\circ} \mathrm{C}$ with $2 \mu \mathrm{g}$ of monocional antibody Y13-259 (Furth et al., 1982) followed by incubation with rabbit anti-rat immunoglobulin and protein A-Sepharose for $1 \mathrm{hr}$ at $4^{\circ} \mathrm{C}$. Immunoprecipitates were washed with buffer $A$, and the nucleotides were eluted from p21 by incubating with $10 \mu \mathrm{l}$ of $1 \%$ SDS and $20 \mathrm{mM}$ EDTA for $5 \mathrm{~min}$ at $65^{\circ} \mathrm{C}$. Two microliters of eluted nucleotides was resolved by chromatography on polyethyleneimine impregnated cellulose plates in $1 \mathrm{M} \mathrm{LiCl}$.

The chromatography plates were exposed for autoradiography using $X$-ray film and phosphor imaging plates for quantitation with the Phosphorlmager from Molecular Dynamics. The Phosphorlmager offers increased sensitivity over $X$-ray film, and the signal is linear in the range of 10 to $1 \times 10^{7}$ disintegrations per $\mathrm{mm}^{2}$ (Johnston et al., 1990). The chromatography plates were exposed to the storage phosphor screens for $12 \mathrm{hr}$, and the plates were scanned using the Phosphorlmager. The image generated was graphically divided into regions, and the disintegrations were analyzed using the ImageQuant software.

\section{Acknowledgments}

We are grateful to Scott Davey for help with the Phosphorlmager. We thank David Gutmann, Margaret Wallace, and Lone Andersen for helpful discussion and comments and Patricia Bird and Bernice Sandri for assistance in the preparation of the manuscript. This work was supporled by grants from the National Institutes of Health, The American Cancer Society, and by the Pfizer Biomedical Research Award. R. B. and D. M. are supported by NIH fellowships. M. W. is an American Cancer Society Research Professor. F. C. is an Associate Investigator of the Howard Hughes Medical Institute.

The costs of publication of this article were defrayed in part by the payment of page charges. This article must therefore be hereby marked "advertisement" in accordance with 18 USC Section 1734 solely to indicate this fact

Received October 23, 1990

\section{References}

Adari, H., Lowy, D., Willumsen, B., Der, C., and McCormick, F. (1988) Guanosine triphosphatase activating protein (GAP) interacts with the p21 ras effector binding domain. Science 240, 518-521.

Altschul, S., Carroll, R., and Lipman, D. (1989). Weights for data related by a tree. J. Mol. Biol. 207, 647-653.

Altschul, S., Gish, W., Miller, W., Myers, E., and Lipman, D. (1990). Basic local alignment search tool. J. Mol. Biol., in press.

Ballester, R., Michaeli, T., Ferguson, K., Xu, H.-P., McCormick, F., and Wigler, M. (1989). Genetic analysis of mammalian GAP expressed in yeast. Cell 59, 681-686.

Barbacid, M. (1987). ras genes. Annu. Rev. Biochem. 56, 779-827.

Barker, D., Wright, E., Nguyen, K., Cannon, L., Fain, P., Goldgar, D., Bishop, D., Carey, J., Baty, B., Kivlin, J., Willard, H., Waye, J., Greig, G., Leinwand, L., Nakamura, Y., O'Connell, P., Leppert, M., Lalouel, J. White, R., and Skolnick, M. (1987). Gene for von Recklinghausen neurofibromatosis is in the pericentric region of chromosome 17 . Science 236, 1100-1102.

Bar-Sagi, D., and Feramisco, J. (1985). Microinjection of the ras oncogene protein into PC12 cells induces morphological differentiation. Cell 42, 841-848.

Broek, D., Toda, T., Michaeli, T., Levin, L., Birchmeier, C., Zoller, M. Powers, S., and Wigler, M. (1987). The S. cerevisiae CDC25 gene product regulates the RAS/adenylate cyclase pathway. Cell 48, 789-799. Buchberg, A., Cleveland, L., Jenkins, N., and Copeland, N. (1990). Sequence homology shared by neurofibromatosis type-1 gene and IRA-1 and IRA-2 negative regulators of the RAS cyclic AMP pathway. Nature 347, 291-294.

Cales, C., Hancock, J., Marshall, C., and Hall, A. (1988). The cytoplasmic protein GAP is implicated as the target for regulation by the ras gene product. Nature 332, 548-551.

Camonis, J., Kalekine, M., Bernard, G., Garreau, H., Boy-Marcotte, E. and Jacquet, M. (1986). Characterization, cloning and sequence analysis of the CDC25 gene which controls the cyclic AMP level of Saccharomyces cerevisiae. EMBO J. 5, 375-380.

Cawthon, R., Weiss, R., Xu, G., Viskochil, D., Culver, M., Stevens, J., Robertson, M., Dunn, D., Gesteland, R., O'Connell, P., and White, R. (1990). A major segment of the neurofibromatosis type 1 gene: cDNA sequence, genomic structure, and point mutations. Cell 62, 193-201. Colicelli, J., Birchmeier, C., Michaeli, T., O'Neill, K., Riggs, M., and Wigler, M. (1989). Isolation and characterization of a mammalian gene encoding a high-affinity cAMP phosphodiesterase. Proc. Natl. Acad. Sci. USA 86, 3599-3603.

Colicelli, J., Birchmeier, C., Rodgers, L., Riggs, M., and Wigler, M (1991). Expression of three mammalian CDNAs which interfere with RAS function in S. cerevisiae. Proc. Natl. Acad. Sci. USA, in press.

Crowe, F., Schull, W., and Neel, J. (1956). A Clinical, Pathological, and Genetic Study of Multiple Neurofibromatosis (Springfield, Illinois: Charles C. Thomas).

Fountain, J., Wallace, M., Bruce, M., Seizinger, B., Menon, A., Gusella, J., Michels, V., Schmidt, M., Dewald, G., and Collins, F. (1989). Physical mapping of a translocation breakpoint in neurofibromatosis. Science 244, 1085-1087.

Furth, M., Davis, L., Fleurdelys, B., and Scolnick, E. (1982). Monoclonal antibodies to the p21 products of the tranforming gene of Harvey sarcoma virus and of the cellular ras family. J. Virol. 43, 294-304.

Goldgar, D., Green, P., Parry, D., and Mulvihill, J. (1989). Multipoint linkage analysis in neurofibromatosis type 1: an international collaboration. Am. J. Hum. Genet. 44, 6-12.

Gross, M., Sweet, R., Sathe, G., Yokoyama, S., Fasano, O., Goldfarb, M., Wigler, M., and Rosenberg, M. (1985). Characterization of human H-RAS proteins produced in E. coli. Mol. Cell. Biol. 5, 1015-1024.

Hagag, N., Halegoua, S., and Viola, M. (1986). Inhibition of growth factor-induced differentiation of PC12 cells by microinjection of antibody to ras p21. Nature 319, 680-682.

Ito, H., Fukuda, Y., Murata, K., and Kimura, A. (1983). Transformation 
of intact yeast cells treated with alkali cations. J. Bacteriol. 153, $163-168$.

Johnston, R., Pickett, S., and Barker, D. (1990). Autoradiography using storage phosphor technology. Electrophoresis 11, 355-360.

Karlin, S., and Altschul, S. F. (1990). Methods for assessing the statistical significance of molecular sequence features by using general scoring schemes. Proc. Natl. Acad. Sci. USA 87, 2264-2268.

Knudson, A., Jr., Hethcote, B., and Brown, B. (1975). Mutation and childhood cancer; a probabilistic model for the incidence of retinoblastoma. Proc. Natl. Acad. Sci. USA 72, 5116-5120.

Lipman, D., Altschul, S., and Kececioglu, J. (1989). A tool for multiple sequence alignment. Proc. Natl. Acad. Sci. USA 86, 4412-4415.

Maniatis, T., Fritsch, E., and Sambrook, J. (1982). Molecular Cloning A Laboratory Manual (Cold Spring Harbor, New York: Cold Spring Harbor Laboratory).

Marshall, M., Gibbs, J., Scolnick, E., and Sigal, I. (1987). Regulatory function of the Saccharomyces cerevisiae RAS C-terminus. Mol. Cell. Biol. 7, 2309-2315.

Marshall, M., Hill, W., Ng, A., Vogel, U., Schaber, M., Scolnick, E. Dixon, R., Sigal, I., and Gibbs, J. (1989). A C-terminal domain of GAP is sufficient to stimulate ras p21 GTPase activity. EMBO J. 8 , $1105-1110$

Matsumoto, K., Uno, I., and Ishikawa, T. (1985). Genetic analysis of the role of CAMP in yeast. Yeast 1, 15-24.

Noda, M., Ko, M., Ogura, A., Liu, D., Amano, T., Tanako, T., and Ikawa, $Y$. (1985). Sarcoma viruses carrying ras oncogenes induce differentiation-associated properties in a neuronal cell line. Nature 318, 73-75.

O'Connell, P., Leach, R., Cawthon, R., Culver, M., Stephens, J. Viskochil, D., Fournier, R., Rich, D., Ledbetter, D., and White, R. (1989) Two NF1 translocations map within a 600 kilobase segment of 17q11.2. Science 244, 1087-1088.

Posfai, J., Bhagwal, A., Posfai, G., and Roberts, R. (1989). Predictive motifs derived from cytosine methyltransferases. Nucl. Acids Res. 17 2421-2435.

Powers, S., O'Neill, K., and Wigler, M. (1989). Dominant yeast and mammalian RAS mutants that interfere with the CDC25-dependent activation of wild-type RAS in S. cerevisiae. Mol. Cell. Biol. 9, 390-395. Riccardi, V., and Eichner, J. (1986). Neurofibromatosis: Phenotype, Natural History, and Pathogenesis (Baltimore: Johns Hopkins University Press).

Robinson, L., Gibbs, J., Marshall, M., Sigal, I., and Tatchell, K. (1987) CDC25: a component of the RAS-adenylate cyclase pathway in Saccharomyces cerevisiae. Science 235, 1218-1221.

Rothstein, R. (1983). One-step gene disruption in yeast. Meth. Enzymol. 101, 202-211.

Sass, P., Field, J., Nikawa, J., Toda, T., and Wigler, M. (1986). Cloning and characterization of the high affinity CAMP phosphodiesterase of S. cerevisiae. Proc. Natl. Acad. Sci. USA 83, 9303-9307.

Schuler, G., Altschul, S., and Lipman, D. (1990). A workbench for multiple alignment construction and analysis. Prot. Struct. Funct. Genet. in press.

Seizinger, B., Rouleau, G., Ozelius, L., Lane, A., Faryniarz, A., Chao, M., Huson, S., et al. (1987). Genetic linkage of von Recklinghausen neurofibromatosis to the nerve growth factor receptor gene. Cell 49 589-594.

Sherman, F., Fink, G., and Hicks, J. (1986). Laboratory Course Manual for Methods in Yeast Genetics (Cold Spring Harbor, New York: Cold Spring Harbor Laboratory)

Shimizu, K., Goldfarb, M., Suard. Y., Perucho, M., Li, Y., Kamata. T. Feramisco, J., Stavnezer, E., Fogh, J., and Wigler, M. (1983). Three human transforming genes are related to the viral ras oncogenes. Proc. Natl. Acad. Sci. USA 80, 2112-2116.

Szeberenyi, J., Cai, H., and Cooper, G. (1990). Effect of a dominant inhibitory Ha-ras mutation on neuronal differentiation of $\mathrm{PC} 12$ cells. Mol. Cell. Biol. 10, 5324-5332.

Tanaka, K., Matsumoto, K., and Toh-e, A. (1989). IRA1, an inhibitory regulator of the RAS-cyclic AMP pathway in Saccharomyces cerevisiae. Mol. Cell. Biol. 9, 757-768.

Tanaka, K., Nakafuku, M., Satoh, T., Marshall, M., Gibbs, J., Matsumoto, K., Kaziro, Y., and Toh-e, A. (1990a). S. cerevisiae genes IRA1 and IRA2 encode proteins that may be functionally equivalent to mammalian ras GTPase activating protein. Cell 60, 803-807.

Tanaka, K., Nakafuku, M., Tamanoi, F., Kaziro, Y., Matsumoto, K., and Toh-e, A. (1990b). IRA2, a second gene of Saccharomyces cerevisiae that encodes a protein with a domain homologous to mammalian ras GTPase-activating protein. Mol. Cell. Biol. 10, 4303-4313.

Toda, T., Uno, I. Is hikawa, T., Powers, S., Kataoka, T., Broek, D., Cameron, S., Broach, J., Matsumoto, K., and Wigler, M. (1985). In yeast, RAS proteins are controlling elements of the adenylate cyclase. Cell 40 , 27-36.

Trahey, M., and McCormick, F. (1987). A cytoplasmic protein stimulates normal N-ras p21 GTPase, but does not affect oncogenic mutants. Science 238, 542-545.

Trahey, M., Wong, G., Halenbeck, R., Rubinfeld, B., Martin, G., Ladner, M. Long, C. Crosier, W., Watt, K., Koths, K., and McCormick, F. (1988) Molecular cloning of two types of GAP complementary DNA from human placenta. Science 242, 1697-1700.

Vieira, J., and Messing, J. (1987). Production of single-stranded plasmid DNA. Meth. Enzymol. 153, 3-11.

Viskochil, D., Buchberg, A., Xu, G., Cawthon, R., Stevens, J., Wolff, R., Culver, M., Carey, J., Copeland, N., Jenkins, N., White, R., and O'Connell, P. (1990). Deletions and a translocation interrupt a cloned gene at the neurofibromatosis type 1 locus. Cell 62, 187-192.

Vogel, U., Dixon, R., Schaber, M., Diehl, R., Marshall, M., Scolnick, E., Sigal, I., and Gibbs, J. (1988). Cloning of bovine GAP and its interaction with oncogenic ras p21. Nature 335, 90-93

Wallace, M., Marchuk, D., Andersen, L., Letcher, R., Odeh, H., Saulino, A., Fountain, J., Brereton, A., Nicholson, J., Mitchell, A., Brownstein B., and Collins, F. (1990). Type 1 neurofibromatosis gene: identification of a large transcript disrupted in three NF1 patients. Science 249, 181-186.

Xu, G., O'Connell, P., Viskochil, D., Cawthon, R., Robertson, M., Culver, M., Dunn, D., Stevens, J., Gesteland, R., White, R., and Weiss. R. (1990). The neurofibromatosis type 1 gene encodes a protein related to GAP. Cell 62, 599-608.

Yatani, A., Okabe, K., Polakis, P., Halenbeck, R., McCormick, F., and Brown, A. (1990). ras p21 and GAP inhibit coupling of muscarinic receptors to atrial $\mathrm{K}^{+}$channels. Cell $61,769-776$.

Zhang, K., DeClue, J., Vass, W., Papageorge, A., McCormick, F., and Lowy, D. (1990). Suppresion of c-ras transformation by GTPaseactivating protein. Nature $346,754-756$. 